\title{
ETIOLOGY OF URINARY TRACT INFECTION IN SCHOLAR CHILDREN
}

\author{
UBIRAJARA BARROSO JR., DANILO V. BARROSO, MODESTO JACOBINO, ANTONIO J. \\ VINHAES, ANTONIO MACEDO JR., MIGUEL SROUGI \\ Section of Pediatric Urology, Division of Urology, São Rafael Hospital, Professor Edgard Santos College \\ Hospital, Federal University of Bahia, Salvador, BA, and Paulista School of Medicine, Federal University of \\ São Paulo, São Paulo, SP, Brazil
}

\begin{abstract}
Objective: To prospectively assess the prevalence of vesicourethral dysfunction in children over 3 years old, comparing it with the occurrence rate for other potential factors that cause urinary infection in this age range.

Materials and Methods: 36 girls and 9 boys were assessed, with mean age of 6.4 years, ranging from 3 to 13.9 years. These children were prospectively assessed regarding the presence of symptoms of lower urinary tract dysfunction. These data were compared with the retrospective assessment of other potential risk factors for urinary infection. Ultrasonography was performed in 28 children and voiding cystourethrogram was performed in 26 patients.

Results: Vesicourethral dysfunction was diagnosed in 39 (87\%) of the 45 children with urinary infection. Among these 39 patients, all had voiding urgency, 30 (77\%) had urinary incontinence, $12(31 \%)$ pollakiuria and $3(8 \%)$ presented infrequent voiding. Vaginal discharge was evidenced in 8 $(22 \%)$ girls and phimosis in $2(22 \%)$ boys. Obstipation was diagnosed in $10(22 \%)$ cases. Significant post-voiding residue was detected in $4(13 \%)$ of the 28 cases assessed. Vesicoureteral reflux was evidenced in 5 (19\%) of the 26 patients who underwent voiding cystourethrogram. In only 2 (4\%) cases there was not an apparent cause for the infection.

Conclusion: Vesicourethral dysfunction is a major cause of urinary infection in children with ages above 3 years old. In cases where voiding dysfunction in not present, other predisposing factors must be assessed. However, only $4 \%$ of the patients did not present an apparent urologic cause for the infection.
\end{abstract}

Key words: urinary tract infections; children; bacteriuria; voiding dysfunction Int Braz J Urol. 2003; 29: 450-4

\section{INTRODUCTION}

Urinary infection is a frequent event in the pediatric population, which occurs in approximately $1 \%$ of boys and up to $3 \%$ of girls in scholar age (1). Urinary infection in the childhood is always regarded as complicated, due to the high number of associated abnormalities and to the high risks of irreversible renal lesion in cases where the treatment is delayed $(2,3)$. Even though the treatment for urinary infec- tion is extremely effective, recurrence is frequent, and occurs in approximately $40 \%$ in females and $32 \%$ in males, following a first episode of infection (4). This high recurrence index can be due to several factors, among them the development of bacterial resistance to the antibiotic, insufficient dosing and period of medication, low immunity and persistence of the etiologic factor.

The probable causes of urinary infection in scholar age children, who present already voluntary 
voiding, have been discussed for a long time. Historically, the major cause of urinary infection in children is vesicoureteral reflux. Other causes include obstipation, vaginal discharge and phimosis. Just recently, in children with non neurological or anatomical alteration, the lower urinary tract dysfunction (vesicourethral dysfunction) was pointed out as a significant cause of infection $(5,6)$. In such cases, vesical instability and urinary retention are probable predisposing factors. The objective of this study is to prospectively assess the prevalence of vesicourethral dysfunction in children over 3 years old that presented urinary tract infection and had no neurological alteration or anatomical abnormality of the lower urinary tract. This was compared with the occurrence rate of other potential factors that cause urinary infection in this age range.

\section{MATERIALS AND METHODS}

From January 2001 to September 2002, 45 children over 3 years old, who already presented voluntary voiding and came to the outpatient service with antecedents of urinary tract infection, were analyzed. Patients were prospectively assessed regarding the presence of symptoms of lower urinary tract infection (vesicourethral dysfunction).Symptoms were assessed after treating the urinary infection. The protocol consisted of questions about the occurrence of voiding urgency and diurnal urinary incontinence. The questionnaire was conducted by the physicians and answered by the children's parents. A voiding diary was completed for every child, recording the voiding frequency and the volume urinated per day. Infrequent voiding was defined as a voiding frequency of less than 4 times a day. Vesicourethral dysfunction was defined as the presence of voiding urgency symptoms, or infrequent voiding, with or without diurnal urinary incontinence, in the absence of urinary infection and neurological alterations.

The medical records of the same 45 patients were analyzed and a retrospective analysis of other potential risk factors for urinary infection was performed. Children were systematically assessed for the presence of vaginal discharge in girls, phimosis in boys and obstipation. A great deal of children was assessed for vesicoureteral reflux and post-voiding residue. Pyelonephritis was defined as the presence of urinary infection associated with fever.

Patients with urinary infection associated with neurological disorders of any nature and obstructive anatomical anomalies such as posterior urethral valve, megaureter, ureterocele and ectopic ureter, were excluded. Two patients were excluded due to doubt regarding the presence of urinary infection, since despite the characteristic symptoms, there was no laboratory corroboration. Patients who had not entered the voluntary voiding stage, were not considered.

Thirty-six girls and 9 boys were assessed, with mean age of 6.4 years, ranging from 3 to 13.9 years. Ultrasonography was performed in 28 children, measuring post-voiding residue, which were considered significant when it was higher than $10 \%$ of the bladder's functional capacity. Voiding cystourethrogram was performed in 26 patients. The Fisher test was used for differential statistical analysis. The difference was considered significant when "p" value was lower than 0.05 .

\section{RESULTS}

Vesicourethral dysfunction was diagnosed in $39(87 \%)$ of the 45 children with urinary infection. Among the 39, all presented voiding urgency, 30 (77\%) had urinary incontinence, $12(31 \%)$ pollakiuria and $3(8 \%)$ presented infrequent voiding. Vaginal discharge was evidenced in $8(22 \%)$ girls and phimosis in $2(22 \%)$ boys. Obstipation was diagnosed in 10 $(22 \%)$ cases. Significant post-voiding residue was detected in $4(13 \%)$ of the 28 cases assessed. Vesicoureteral reflux was evidenced in $5(19 \%)$ of the 26 patients who underwent voiding cystourethrogram.

Of the 6 cases who presented with urinary infection, but without vesicourethral dysfunction, 5 were female and one was male. Among these cases, obstipation, vesicoureteral reflux, high post-voiding residue and vaginal discharge were evidenced in one patient each. In 2 (4\%) cases there was not an apparent cause of the infection.

The characteristics of the urinary infection were separately assessed between children with and 
without vesicourethral dysfunction. Of the 6 patients without vesicourethral dysfunction, one presented just a history of cystitis, $4(67 \%)$ only pyelonephritis and one had both cystitis and pyelonephritis. Of those with vesicourethral dysfunction, 11 had only cystitis, 24 $(61,5 \%)$ only pyelonephritis and 4 presented cystitis and pyelonephritis. This difference was not statistically significant.

\section{DISCUSSION}

There are several causes of urinary infection in childhood. Main predisposing factors are short female urethra, vaginal discharge, phimosis, obstipation and the presence of post-voiding urinary residue. In the last decade, vesicourethral dysfunction has been given a greater importance as a relevant risk factor for this kind of infection. However, to our knowledge, the incidence of vesicourethral dysfunction in children with urinary infection has not been well established. In our series, vesicourethral dysfunction was by far the main risk factor for urinary infection, being present in $87 \%$ of cases in children above 3 years old with voluntary voiding. Among these cases, all were related to symptoms of voiding urgency, $77 \%$ to urinary incontinence, $31 \%$ to pollakiuria and $8 \%$ to infrequent voiding. With a lower incidence, $22 \%$ presented obstipation, 22\% vaginal discharge, $22 \%$ phimosis, $19 \%$ had vesicoureteral reflux and $13 \%$ presented a high post-voiding residue. Even though the relationship between vesicourethral dysfunction and urinary infection is well known $(5,6)$, to our knowledge, this is the first study ever to compare the several factors that predispose to urinary infection in older children.

There are several factors that can predispose children with vesicourethral dysfunction to urinary tract infection. According to Koff \& Murtagh, involuntary contractions of the bladder are the main cause (5). This is confirmed by our study, where $87 \%$ of the children with infection presented voiding urgency, which is a clinical sign of involuntary contraction of the detrusor. According to this theory, the uninhibited contraction is opposed by a voluntary contraction of the external sphincter $(7,8)$. This would lead, in girls, to the retrograde flow of urine to the bladder, bringing back bacteria from the urethra's distal portion. Another theory is that continued uninhibited vesical contractions could produce ischemia of the vesical mucosa, decreasing the host's resistance to bacterial action $(9,10)$. In this case, the contracted bladder would offer a higher vascular resistance and, with the presence of a compensatory hypertrophy of the detrusor, there would be a greater requirement of blood supply. This would lead to transitory ischemia, propitiating the infection. However, it is still not known if the phasic involuntary contractions, typical of non-neurogenic vesical dysfunction, produce ischemia. Additionally, muscle hypertrophy would occur in a later stage of dysfunction, and the urinary infection occurs also in initial stages. It is believed that the detrusor hypertrophy and hypoxia would cause a higher contractility related to the neuronal direct stimulation, as well as a higher sensitivity to acetylcholine, predisposing to uninhibited contractions (11). In such cases, those 2 factors would jointly act for the infection genesis. Another important factor is urinary retention; children who urinate with a low frequency or accumulate post-voiding residue have a higher predisposition to urinary infection (12). However, only $13 \%$ of our cases that were assessed through vesical ultrasonography had a high post-voiding residue.

Other researchers try to justify the appearance of vesicourethral dysfunction following an episode of urinary infection. Animal studies show that when the infection is intense enough to cause rupture of the endothelium, there is an afferent stimulus in response to vesical distension (13), with the prompt onset of rhythmic vesical contractions (14). Immunohistochemical studies of the inflammated bladder showed a an increased expression of nociceptive neuropeptides such as substance $\mathrm{P}$ and calcitonine generelated peptides, described in women with vesical instability (15). The difficulty in obtaining an experimental model to study the vesicourethral dysfunction hampers a better knowledge about its relation with urinary infection. However, the theory that urinary infection generates vesicourethral dysfunction, does not justify its appearance in those cases that never presented urinary infection, as well as it does not jus- 
tify the absence of dysfunction in some children with documented urinary infection.

Vesicourethral dysfunction can also facilitate, or act concomitantly to other risk factors for urinary infection. For example, during the uninhibited contraction of the detrusor, in addition to the existence of a voluntary contraction of the external urethral sphincter and, consequently, of the pelvic floor, the child compresses the vagina with the hands or the thighs, which facilitates, in cases of incontinence, the entrance of urine into the vagina, causing irritation and vaginal discharge. We theorize that this would change the vaginal bacterial flora, predisposing to urinary infection. The association between vesicourethral dysfunction and obstipation is common, and both must be considered and addressed jointly (16). These patients are more susceptible to recurrent urinary infection, because in addition to the fact that obstipation worsens the vesicourethral dysfunction, the fecal bacteria end up colonizing the urinary tract. Another associated factor that can facilitate the occurrence of urinary infection is vesicoureteral reflux (17). The relation between reflux and vesicourethral dysfunction is quite known already. The persistence of dysfunction predisposes to the continuity of vesicoureteral reflux due to unbalance of the ureteral submucosal tunnel. However, Barroso et al. demonstrated that even after the surgical resolution of the reflux, patients maintain the risk for urinary infection and that children with vesicourethral dysfunction have a recurrence rate for urinary infection that is approximately 3 times higher than that of children without dysfunction (18). It demonstrates that vesicourethral dysfunction, and not the reflux, is the main cause of urinary infection.

Among all the assessed cases, only 2 did not present any of the risk factors for infection. It is possible that episodes of low frequency in voiding, with prolonged retention of urine within the bladder, not perceived by the parents, can be the cause of infection in these children. Some mothers advise the child not to urinate in public restrooms afraid of the local sanitary state, which causes them to have some periods of urine retention.

One critic that can be made to our study is the retrospective analysis of a part of data, which can be responsible for the decreased frequency of factors that were analyzed as causing urinary infection, when compared with the rate of vesicourethral dysfunction, whose assessment was prospective. However, patients were systematically questioned about fecal rhythm and vaginal discharge and boys were evaluated for phimosis, which, in principle, minimizes this kind of error. At the moment, these factors are included in the prospective questionnaire as well.

\section{CONCLUSION}

According to data from this study, vesicourethral dysfunction was the main factor associated with urinary infection in children over 3 years old, occurring in $87 \%$ of the cases. Therefore, the assessment of every patient with urinary infection is mandatory, for symptoms of urgency, urge incontinence and low daily voiding frequency. In cases where voiding dysfunction is not present, other predisposing factors must be assessed. Only $4 \%$ of patients did not have an apparent urologic cause for the infection. The influence of treatment on these causal factors is currently under study.

\section{REFERENCES}

1. American Academy of Pediatrics. Practice parameter: the diagnosis, treatment, and evaluation of the initial urinary tract infection in febrile infants and young children. Pediatrics. 1999; 103: 843-56.

2. Ransley PG, Risdon R: The pathogenesis of reflux nephropathy. Contrib Nephrol. 1979; 16: 90-7.

3. Shortliffe DLM: Urinary tract infections in infants and children. In Campbell's Urology. Ed by Walsh PC, Retik AB, Vaughan ED Jr, Wein A. Philadelphia, Saunders. 2002; pp 1846-84.

4. Winberg J, Andersen HJ, Bergstrom T, Jacobsson B, Larson H, Lincoln K: Epidemiology of symptomatic urinary tract infection in childhood. Acta Paediatr Scand Suppl. 1974; 252: 1-20.

5. Koff SA, Murtagh DS: The unhibited cladder in children: effect of treatment on recurrence of urinary infection and on vesicoureteral reflux. J Urol. 1983; 130: 1138-41.

6. Snodgrass W: The impact of treated dysfunctional voiding on the nonsurgical management of vesicoureteral reflux. J Urol. 1998; 160: 1823-5. 
7. Passerini-Glazel G, Cisternino A, Camuffo MC, Ferrarese P, Aragona F, Artibani W: Videourodynamic studies of minor voiding dysfunction in children: an overview of 13 years' experience. Scand J Urol Nephrol Suppl. 1992; 141: 70-84.

8. Fernandes E, Vernier R, González R: The unstable bladder in children. J Pediatr. 1991; 118: 831-7.

9. Koff SA, Lapides J, Piazza DH: Association of urinay tract infection and reflux with unhibited bladder contractions and voluntary sphincteric obstruction. J Urol. 1979; 122: 373-6.

10. Lapides J, Diokno AC: Persistence of the infant bladder as a cause of urinary infection in girls. J Urol. 1970; 103: 243-8.

11. Brading AF, Turner WH: The unstable bladder: towards a commom mechanis. Br J Urol. 1994; 73: 3-8.

12. Smith EM, Elder JS: Double antimicrobial prophylaxis in girls with breakthrough urinary tract infections. Urology. 1994; 43: 708-12.

13. McMahon SB: Neuronal and behavioural consequences of chemical inflammation of rat urinary bladder. Agents Actions. 1988; 25: 231-3.
14. Callsen-Cencic P, Mense S: Expression of neuropeptides and nitric oxide synthase in neurons innervating the inflamed rat urinary bladder. J Autonom Nerv Syst. 1997; 65: 33-44.

15. Smet P, Moore KH, Jonavicius J: Distribution and colocalisation of calcitonin gene-related peptide, tachykinins and vasoactive intestinal polypeptide in normal and idiopathic unstable human urinary bladder. Lab Invest. 1997; 77: 37-49.

16. Koff SA, Wagner TT, Jayanthi VR: The relationship among dysfunctional elimination syndromes, primary vesicoureteral reflux and urinary tract infections in children. J Urol. 1988; 160: 1019-22.

17. Barroso U Jr., Macedo A, Srougi M: Correlação entre disfunção miccional e refluxo vesicoureteral em crianças com disfunção miccional. Braz J Urol. 1999; 25: 532-6.

18. Barroso U Jr, Jednak R, Barthold JS, González R: Outcome of ureteral reimplantation in children with the urge syndrome. J Urol. 2001; 166: 1031-5.

Correspondence address:

Dr. Ubirajara Barroso Jr.

Rua Alameda dos Antúrios, 212 / 602

Salvador, BA, 40280-620, Brazil

E-mail: ubarroso@uol.com.br 